\title{
Opciones políticas, comunas y votos. Distribución territorial de los apoyos electorales a la Alcaldía de Santiago de Cali 2003-2011*
}

\author{
Adolfo A. Abadía** \\ (aabadia@icesi.edu.co)
}

Artículo de investigaciòn recibido el 28/11/2014 y aprobado el 19/12/2014

Cómo citar este artículo:

\begin{abstract}
ABADÍA, Adolfo A. (2014). “Opciones políticas, comunas y votos. Distribución territorial de los apoyos electorales a la Alcaldía de Santiago de Cali 2003-2011". En: Trans-pasando Fronteras, núm. 6, pp. 183-216. Cali, Colombia: Centro de Estudios Interdisciplinarios, Jurídicos, Sociales y Humanistas (CIES), Facultad de Derecho y Ciencias sociales, Universidad Icesi.
\end{abstract}

\begin{abstract}
Resumen
Este artículo estudia la distribución territorial de los apoyos electorales relacionando opciones políticas, comunas y votos a la Alcaldía de Santiago de Cali en 2003, 2007 y 2011. Para tal fin, se propone el cálculo del Índice de Nacionalización como forma de observar la variación del apoyo político a lo largo del territorio municipal. Asimismo, se rastrean las opciones políticas que han participado en las contiendas electorales desde la primera elección popular de Alcaldes haciendo una distinción entre

\footnotetext{
El autor quiere aprovechar la oportunidad para agradecer a los profesores Juan Carlos Gómez y Juan José Fernández por sus pertinentes comentarios, a la profesora Margarita Batlle por sus valiosas recomendaciones y, especialmente, al profesor Juan Pablo Milanese por su acompañamiento, observaciones y por la oportunidad de continuar con esta investigación de manera colaborativa. Este artículo forma parte del proyecto denominado Grado de institucionalización del sistema de partidos de Santiago de Cali. Elecciones para la Alcaldia 2003, 2007 y 2011, con el cual se optó por el título de politólogo. Una versión de este trabajo fue presentado en el III Congreso de Ciencia Política ACCPOL 2014.

** Politólogo de la Universidad Icesi (Cali, Colombia). Asistente editorial de la Oficina de Publicaciones de la Facultad de Derecho y Ciencias Sociales de la misma Universidad. Correo personal: adolfoabadia@yahoo.es - http://orcid.org/0000-0002-9034-2156
} 
partidos políticos, movimientos políticos y candidaturas independientes. Luego, a la luz de los valores que arroja el Índice de Nacionalización, se busca identificar el tipo de relación existente entre los resultados electorales y las comunas en tanto a la moda del estrato socio-económico. Entre los resultados más significativos se advierte, por un lado, la presencia de algunas comunas con resultados electorales significativamente elásticos y otras relativamente estables; por otro lado, la suma de los votos en las "comunas elástica" y las "comunas estables" alcanzan un número importante de votos que, en algunos casos, fue suficiente para hacerse con el cargo de Alcalde de Cali.

Palabras clave: Sistema de partidos; Candidatos independientes; Partidos políticos; Índice de nacionalización; Elecciones locales; Cali-Colombia;

\section{Introducción}

El comportamiento electoral de Santiago de Cali ha sido estudiado desde distintas perspectivas. Uno de los primeros trabajos que dan cuenta de este tema es el de Judith Talbot de Campos y José Francisco Martín (1980), quienes arrojan unas primeras pistas sobre el comportamiento electoral de los caleños de 1978. Luego de un silencio de aproximadamente 30 años, se encuentran, por un lado, trabajos que realizan un rastreo de anomalías e irregularidades que arrojaron los cálculos del riesgo electoral en los resultados a la Alcaldía de Cali de 2003 y 2007 (Polis, 2011), así como los que abordan esta temática desde una perspectiva historiográfica de las élites políticas antes que del comportamiento electoral per se (Crespo, 2010; y Sáenz, 2010a y 2010b). Por otro lado, existen estudios del comportamiento electoral de los caleños a la luz de las campañas publicitarias y los medios de comunicación (Pinto, 2008; Ararat y Londoño, 2012), y del impacto de la descentralización política a partir de los ocho primeros alcaldes electos popularmente (Pinto, 2011 y Correa, 2012). Recientemente, se han desarrollado análisis que abordan la relación entre partidos políticos, electorados y territorio pretendiendo desentrañar cuestiones como la configuración de los apoyos electorales a los candidatos y el nivel de impacto de algunas comunas de la ciudad en relación a la elección de alcaldes en Santiago de Cali (Milanese, 2014; Abadía, 2014; y Abadía y Milanese, 2014). El análisis que ofrece este documento se inscribe en esta última línea de investigación y busca aportar al estudio de la triada partidos políticos, electorado y territorio a nivel subnacional, especialmente, sobre las elecciones a nivel local, en particular para el municipio de Santiago de Cali. 
En Colombia se pueden referenciar estudios que han articulado estos tres elementos, principalmente, desdeunaperspectiva de relacionesclientelares enmarcadas en el contexto del conflicto armado (Dávila y Delgado, 2002; Gutiérrez, 2006; García, 2007 y 2010; y López, 2010). En menor medida, se encuentra estudios del grado de institucionalización del sistema de partidos a partir del cálculo del Índice de Nacionalización (PNS). Esta perspectiva surge, aproximadamente, a inicios del siglo XXI, constituyéndose como una agenda investigativa del sistema de partidos latinoamericano relativamente joven (ver Jones y Mainwaring, 2003; Mainwaring y Zoco, 2007, Lupu 2008; Alemán, 2008; Batlle 2009, Leiras, 2009; Lago, 2010; Cascante, 2010; y Casa 2010). En relación al caso colombiano, existen estudios que abordan esta perspectiva para analizar el grado de nacionalización del sistema de partidos a nivel nacional (ver Batlle y Puyana, 2011); sin embargo, no es usual encontrar estudios del arraigo del electorado por una opción política a partir del análisis de los resultados a nivel subnacional. Este artículo pretende dar algunos pasos en este sentido.

El objetico de este trabajo consiste en explorar la relación existente entre territorio, comportamiento y competencia electoral en el sistema de partidos de la ciudad de Santiago de Cali. Luego, a partir del cálculo del PNS, se pretende ofrecer una respuesta a interrogantes sobre el nivel de nacionalización del sistema de partidos del Municipio de Santiago de Cali, específicamente, ¿cuál es el grado de homogeneidad del comportamiento electoral de los caleños? Una primera hipótesis apunta a la existencia ciertas comunas en el municipio de Santiago de Cali, en particular las de estrato socio-económico más bajo, que tienden a tener mayor incidencia sobre los resultados a la Alcaldía; una segunda hipótesis surge de la idea de que la comunas con mayor incidencia en la elección de alcalde vuelven a jugar este rol decisorio en la siguiente jornada electoral; una tercera hipótesis se desprende de la proposición de un bajo nivel de nacionalización, es decir, poca homogeneidad en la distribución de los apoyos electorales de los partidos y el sistema de partidos de Santiago de Cali.

En suma, este documento se estructuró en cinco secciones de la siguiente manera. La primera sección comprende el fundamento conceptual que da forma a este análisis del comportamiento electoral a la luz del Índice de Nacionalización. La segunda sección hace un ágil recorrido histórico sobre la configuración política de 
Santiago de Cali a partir de las elecciones populares a Alcalde, específicamente, de la elecciones de 2003, 2007 y 2011. La tercera sección consiste en el análisis de los resultados del cálculo del PNS. La cuarta parte explora la relación entre los resultados electorales y las comunas según la moda de los estrato-económico. Finalmente, y a modo de conclusión, se presentan unas reflexiones que se desprenden del desarrollo de este artículo y otras que invitan al estudio del sistema de partidos colombiano a nivel subnacional, como en este caso, a nivel municipal.

\section{Índice de Nacionalización, Partidos políticos y Candidaturas independientes}

El Índice de Nacionalización $(P N S)^{1}$ constituye una herramienta estadística de medición de la distribución de los apoyos electorales en un territorio de competencia determinado (unidad de análisis), el cual se ha consolidado como un significativo indicador del grado de homogeneidad de los resultados electorales en un distrito electoral. El PNS mide la dimensión horizontal ${ }^{2}$ de la competencia electoral, también denominada dispersión (Kasuya, 2008.127), a razón de la distribución territorial de los apoyos políticos (Caramani, 2004). De esta forma, una opción política se concebirá como nacionalizada en la medida en que el coeficiente Gini registre un resultado cercano a 1 , lo que significa un alto nivel de homogeneidad territorial de la distribución del voto por una opción política (Bochsler, 2009; Jones y Mainwaring, 2003; y

$1 \quad$ El Índice de Nacionalización de los partidos politicos (PNS) resulta de la resta con 1 del Coeficiente de Gini; matemáticamente, lo anterior se expresa de la siguiente manera: $\mathrm{PNS}=1-\mathrm{Gi}=\mathrm{n} \Sigma(1-\mathrm{Gi}(\mathrm{Xi})) \mathrm{Pi}=1-\mathrm{n} \Sigma(\mathrm{Gi}(\mathrm{Xi})) \mathrm{Pi}$. El Coeficiente Gini se calcula a partir de la siguiente fórmula: $\mathrm{Gi}=|(\mathrm{n} \Sigma \mathrm{Xi} \mathrm{Yi}+1)-(\mathrm{n} \Sigma \mathrm{Xi}+1 \mathrm{Yi})|$, donde $n$ es igual al número total de partidos, $X i$ es la proporción acumulada que representa el porcentaje de los votos válidos ganados por el Partido $X$ en la circunscripción $i$ dividido por el total de los votos ganados por el mismo partido en todas las circunscripciones, y $Y i$ es la proporción acumulada que representa la circunscripción $i$ del total de las circunscripciones u otras subunidades políticas (Jones 2003, Došek 2011 y Lago, 2014). El Índice de Nacionalización del sistema de partidos $(P S N S)$ se calcula de la siguiente manera: $\mathrm{PSNS}=\mathrm{n} \Sigma(\mathrm{PNSi} \cdot \mathrm{Pi})$, donde $n$ es igual al número total de partidos, y $P$ es igual al porcentaje de votos válidos ganados por el Partido $i$ (Jones 2003).

2 Además de una dimensión horizontal se distingue una Dimensión vertical, la cual hace referencia a la posible correlación que los resultados electorales pueden tener para una misma opción política desde una perspectiva multinevel (local, regional y nacional). En este sentido, un partido esta verticalmente institucionalizado cuando "obtienen proporciones semejantes en las elecciones para cargos de distinto nivel” (Leiras, 2010:212) y presentan candidatos en todas las circunscripciones a lo largo de todo el territorio (Schakel, 2012); por el otro lado, esta dimensión se le conoce también, entre otras maneras, como: “inflación partidista", "agregación” de los partidos, "vínculo (linkage) partidista" (Došek, 2011:7). 
Batlle y Puyana, 2011). En este sentido, una opción política altamente nacionalizada debería alcanzar un porcentaje similar de votos en todas las circunscripciones (Jones y Mainwaring, 2003; Casa, 2010; y Cascante, 2010).

Otro elemento que habla a favor del PNS como apuesta metodológica, radica en su vínculo con los análisis del grado de institucionalización de los sistemas de partidos a la luz de la configuración de las lógicas de la competencia electoral. Así, un alto valor en el cálculo del PNS sería el reflejo de un alto grado de institucionalización del sistema de partidos, lo que resulta beneficioso para un gobierno democrático en términos de estabilidad política y acatamiento a las reglas de juego formales, propiciando en mayor medida a los actores políticos un entorno institucionalizado para competir y esbozar expectativas sobre el futuro próximo, y, a largo plazo, sugiere cierta influencia sobre la eliminación de las condiciones que permiten prácticas como el clientelismo y la corrupción local en relación a la construcción de políticas públicas (Jones y Mainwaring, 2003; Mainwaring y Zoco, 2007; Casa, 2010; Cascante, 2010 y Leiras, 2010). En otras palabras, un sistema de partidos altamente institucionalizado supone mayor "equidad en la implementación de políticas públicas en las diversas zonas geográficas que integran el Estado, y aumenta las posibilidades de los actores partidarios para conformar alianzas en base a cuestiones nacionales" (Casa, 2010:2). Además, los sistemas de partidos institucionalizados son importantes para la generación de legitimidad, debido a que ayudan a estructurar opciones relativas al tipo de líderes que el electorado desea. En este sentido, la democracia confiere a los ciudadanos una oportunidad institucionalizada, regulada y no-violenta (elecciones), para reemplazar a sus líderes y representantes políticos (Mainwaring y Scully, 1995; Mainwaring y Torcal, 2005; y Levitsky 1998 y 2001).

Si bien, la mayoría de los estudios que han involucrado el PNS como instrumento de medición de la distribución de los apoyos electorales se han desarrollado a nivel nacional, este modelo puede también ser utilizado a diferentes niveles subnacionales (Došek y Freidenberg, 2013). De este modo, el PNS permite comprender la evolución de "electorados nacionales y sistemas de partidos nacionales donde priman organizaciones partidistas, programas, campañas y cuestiones que rebasan las fronteras locales o regionales" (Batlle y Puyana, 2011:29-30). En este documento 
se enfoca un nivel subnacional definiendo a los límites urbanos del municipio de Santiago de Cali como unidad de análisis. ${ }^{3}$ Por otra parte, el PNS comprende, por un lado, el Índice de Nacionalización de los Partidos (PNS) ${ }^{4}$, el cual indica cómo se distribuye el apoyo político-electoral por una opción política a lo largo un territorio; y, por el otro, el Índice de Nacionalización del Sistema de Partidos (PSNS) ${ }^{5}$, que mide el grado de impacto del PNS en el sistema de partidos en dicho territorio.

Por otro lado, se propone una definición del Sistema de partidos como el marco del "conjunto de interacciones normadas en la competencia entre partidos" (Mainwaring y Scully, 1995; y Mainwaring y Torcal, 2005) que conlleva implícitamente, primero, la existencia de mínimo dos opciones políticas, que para el caso colombiano, éstas pueden tomar las formas de partidos políticos, movimientos políticos o candidaturas independiente (Chanona, 2008:30); segundo, la existencia de una institucionalidad amparada en normas formales pero susceptibles a ser debatidas y modificadas afín de regular la competencia electoral; tercero, una interacción continua de los elementos constituyentes que condicionan la competencia electoral; finalmente, el reconocimiento de las reglas de juego por parte de los actores políticos anteriormente mencionados y el electorado.

En relación a las formas de participación política que permiten a los ciudadanos "elegir y ser elegido" a cargos de elección popular, se realizó una diferenciación acorde a las formas en que se pueden postular candidaturas: vía aval o vía firmas. La primera consiste en la exclusividad de los partidos y movimientos políticos para presentar candidatos, siempre y cuando siga vigente su personería jurídica. La segunda forma de participación política está amparada a la normatividad vigente de cada país. En Colombia, por ejemplo, se permite a los movimientos sociales, también llamados "Grupos Significativos de Ciudadanos (GSC)", postular candidatos a cargo de elección popular, si y solo si, logran recoger el número de firmas al equivalente

3 Se tomaron las 22 comunas de la ciudad como unidades mínimas. No se tomaron a los barrios (neighbourhoods) como estas unidades por dos razones. Primero, al menos en Santiago de Cali, no en todos los barrios se asignan mesas votación (Abadía y Milanese, 2014), y segundo, este fue el máxino nivel de desagregación obtenido de los resultados electorales.

4 Del inglés, Party Nationalization Score.

5 Del inglés, Party System Nationalization Score. 
del $20 \%$ del resultado de dividir el censo electoral para una circunscripción electoral entre el número de puestos por otorgar; ${ }^{6}$ de esta manera es como se validan las Candidaturas Independientes (CI).

Como se podrá observar, estas dos formas de participación dejan entredicho una disyuniva de cómo conceptualizar a las opciones políticas. Si partimos de entender al partido o movimiento político como el medio instrumental para (1) estructurar la competición electoral; para (2) lograr un identificación simbólica; para (3) formar y sostener gobiernos (gobernabilidad); y para (4) ejercer la representación política a través de la agregación de intereses y pasiones canalizando las expectativas y demandas individuales en un cuerpo objetivo: el partido (Schmitter, 1999). Por el contrario, las CI exigen nuevas variables para entenderlos como actores políticos de elección popular, ya que significan una ruptura con las formas tradicionales de pensarse la política y lo político. Sin embargo, tanto los partidos y movimientos políticos como las candiaturas independientes, al menos por un periodo de gobierno, configuran el canal oficial de comunicación política al establecer vínculos entre ciudadanía y Estado.

En Colombia, la modalidad de candidaturas que inscribirse a partir de la recolecciòn de firmas, representan una alternativa de participación política, frecuentemente, usada por movimientos sociales, por cabecillas de partidos y movimientos políticos que no logran obtener el aval que les permita postularse con los colores de su partido o movimiento político en particular y buscan competir de manera independiente por un cargo de elección popular. Para este caso, este tipo de candidaturas han tenido éxito en dos (2007 y 2011) de las tres jornadas electorales tenidas en cuenta en este documento. Por lo tanto, no es de menospreciar la capacidad que tiene este tipo de candidaturas de impactar en el sistema de partidos de la ciudad de Cali, incluso a nivel departamental y nacional.

\section{Opciones políticas: Santiago de Cali y su configuración política a partir de las elecciones a Alcalde}

Santiago de Cali es la capital del departamento del Valle del Cauca. Con aproximadamente 2,3 millones de habitantes es la tercera ciudad con mayor población de Colombia. Hace un poco más de un cuarto de siglo, para la primera Elección Popular de Alcaldes (EPA)

6 En ningún caso se exigirán más de cincuenta mil firmas para permitir la inscripción de un candidato (Ley 130 de 1994, art. 9) 
en 1987, la ciudad contaba con 1,5 millones de habitantes. Desde ese momento al día de hoy, se han elegido democráticamente por medio del voto popular 9 alcaldes (ver tabla 1). En cuatro ocasiones los candidatos electos no terminaron su mandato por diferentes razones: una renuncia, ${ }^{7}$ dos destituciones ${ }^{8}$ y una suspensión. ${ }^{9}$

En la tabla 1 se puede apreciar que, aproximadamente, hasta las últimas elecciones populares a alcalde del siglo XX, la arena política de Cali reprodujo el fenómeno del bipartidismo, al igual que en muchas otras ciudades de Colombia (Arenas y Escobar, 2012; y Abadía y Milanese 2014). A partir del 2001, la Alcaldía de Cali ha sido conquistada por opciones diferentes al Partido Liberal Colombiano y al Partido Conservador Colombiano, de donde los movimientos políticos y, en particular, las candidaturas independientes, se han hecho espacio en una de las esferas municipales de poder político. Esto da cuenta de una transformación en la configuración política en torno a la identificación de la población a los dos partidos tradicionales de Colombia. ${ }^{10}$ Por otro lado, de la tabla se destaca la evolución de los números de votos válidos. Desde la primera elección popular de alcaldes en la ciudad a la última jornada electoral, el número de votos válidos que ha obtenido el candidato ganador ha triplicado su valor, mientras que el número total de votos válidos se ha duplicado.

$7 \quad$ El alcalde electo para el periodo de 1988-1990, Carlos Holmes Trujillo García, renunció a su cargo para asumir otras responsabilidades a raíz de la muerte de su padre Carlos Holmes Trujillo Miranda.

8 El alcalde electo para el periodo de 1995-1997, Mauricio Guzmán Cuevas, fue destituido en agosto de 1997 por ser detenido por la Fiscalía luego de ser investigado por enriquecimiento ilícito por presuntos nexos con el cartel de Cali en un periodo en el que el país estuvo marcado por el proceso 8000. Luego, el alcalde electo para el periodo de 2004-2007, Apolinar Salcedo Caicedo, fue destituido por la Procuraduría General de la Nación en mayo de 2007 por ambivalencias en el contrato de 'modernización' del recaudo de impuestos del municipio con la empresa "Si Cali".

9 El alcalde electo para el periodo de 2008-2011, Jorge Iván Ospina Gómez, a menos de un mes de culminar su gestión en el cargo, fue suspendido por inasistencia a sesiones del Consejo Municipal de Política Social (COMPOS) en donde se discutían aspectos de protección integral a los niños, niñas y adolescentes.

10 Cabe mencionar que tanto el Partido Liberal como el Partido Conservador han desistido de participar en algunas de las contiendas electorales. Por ejemplo, el Partido Liberal no presentó candidato en las elecciones a alcalde de 2007 y el Partido Conservador desiste de participar en el 2003 y 2007; sin embargo, esto no significa que hayan desaparecido de la arena política de la ciudad de Cali. Antes bien, su apoyo oficial, o extraoficial, permitió esbozar expectativas acerca a algunas candidaturas que se perfilarían como ganadoras gracias a este directo o indirecto favorecimiento. 


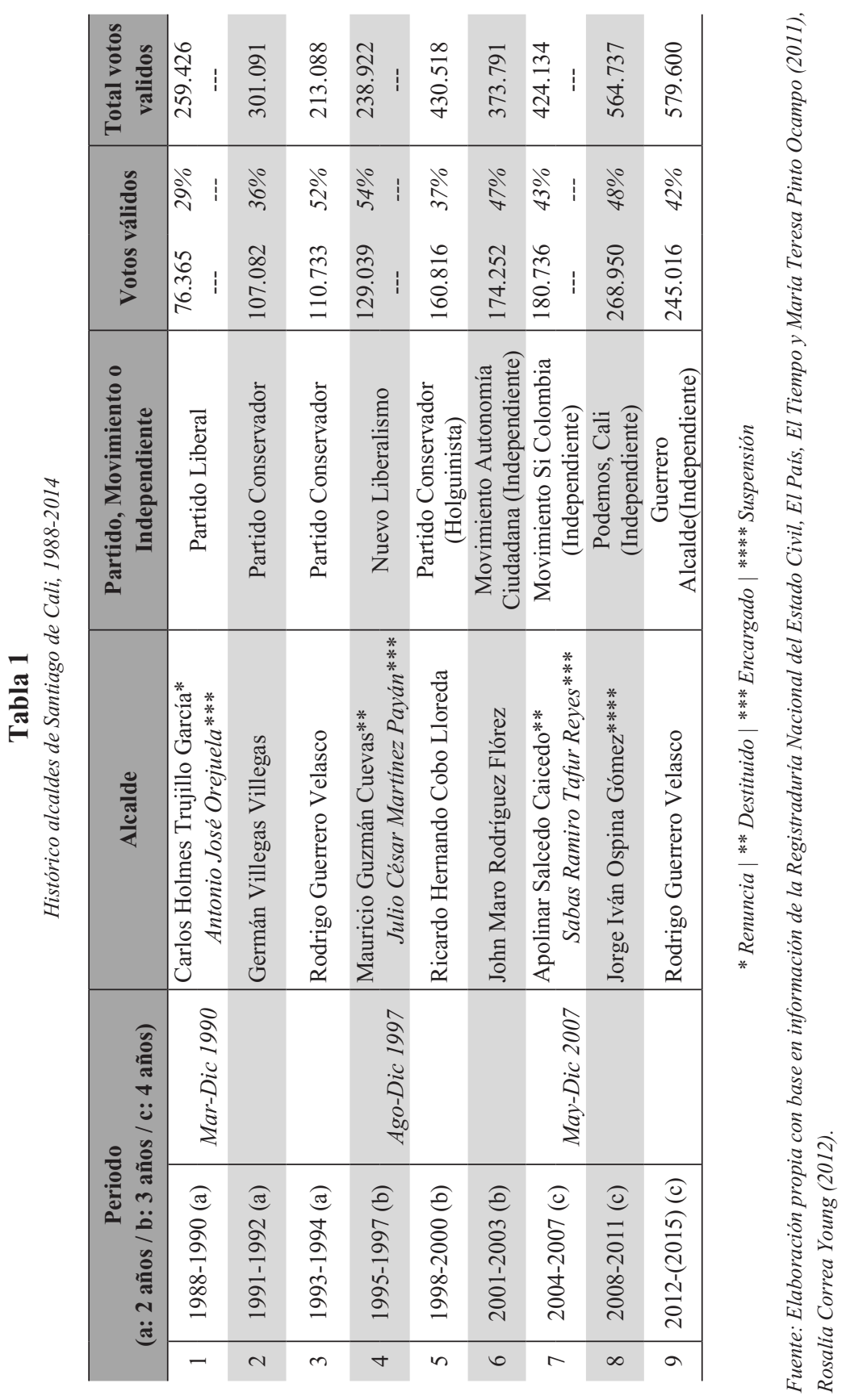


Partidos, movimientos políticos y candidaturas independientes

Como se puede detallar en la tabla 2, los tipos de candidaturas han sido muy variados. En el 2003 todos los candidatos a alcalde obtuvieron el aval de un partido o movimiento político, situación que cambia notoriamente en las siguientes dos jornadas electorales. En el 2007 y 2011 se avalaron por medio de firmas, y con éxito, las candidaturas a alcalde, entre ellas, la de las opciones ganadoras. En las tres jornadas electorales se han registrado diferentes tipos de opciones políticas, entre ellos partidos, movimientos políticos y candidaturas independientes, para un total de 26 candidaturas en competencia, 8, 9 y 9 en el 2003, 2007 y 2011, respectivamente (ver tabla 2). Como se observa en gráfico 1, en el 2003 la disputa electoral sobresale por la superioridad del número de movimientos políticos en competencia. En total fueron 7 movimientos y 1 partido político quienes se enfrentaron en las urnas. Al 2007 la competencia electoral presenta un relativo equilibrio entre 2 partidos, 4 movimientos y 3 candidaturas independientes. Finalmente, para el 2011 este panorama cambia a 5 partidos, 1 movimiento político y 3 candidatura independientes en competencia por la alcaldía de Cali. En congruencia con lo anterior, la tendencia que registra el número de partidos es la siguiente:

\section{Gráfico 1}

Tipos de candidaturas a la Alcaldia de Cali. Partido, movimientos o candidaturas independientes, 2003, 2007 y 2011

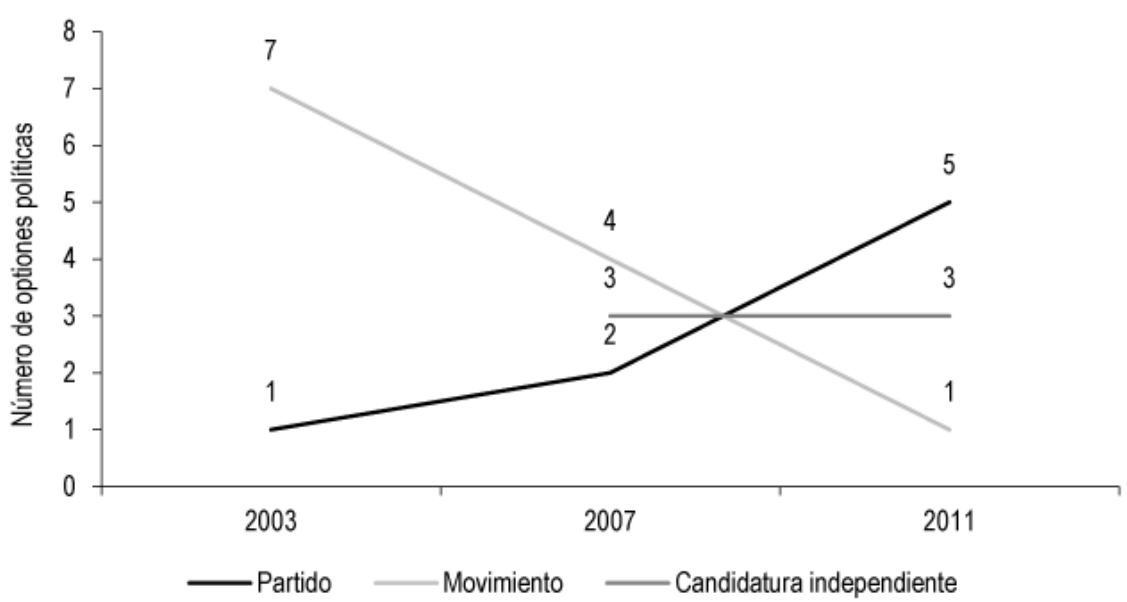

Fuente: Elaboración propia con base en información de la Registraduría Nacional del Estado Civil. 


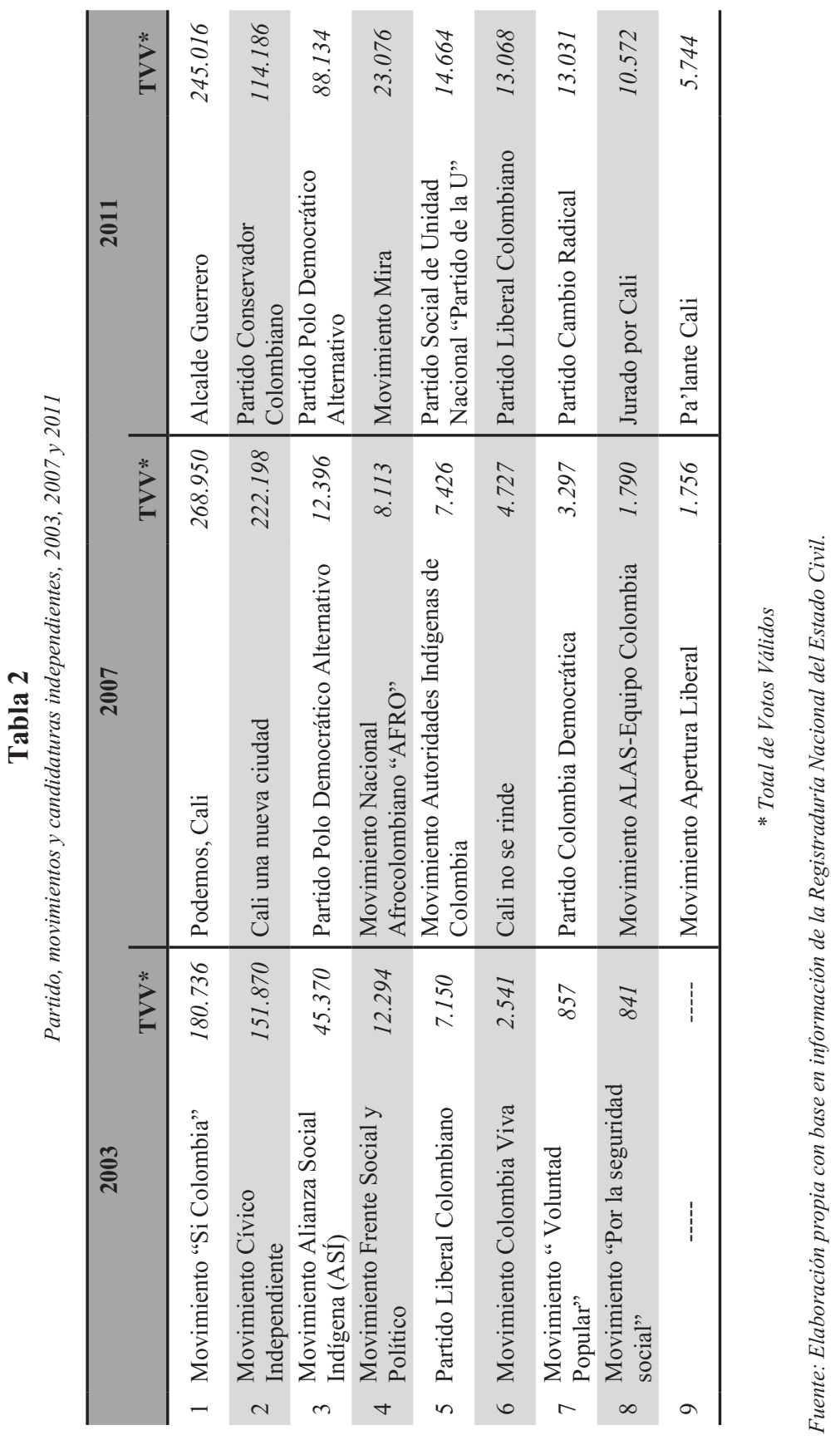


el número de partidos políticos aumentan mientras que el número de movimientos políticos disminuye. Por su parte, las candidaturas independientes mantienen constante su participación desde que emergen en la arena política de la competencia a la Alcaldía de Cali.

En términos de regularidad en la participación electoral de las opciones políticas, a pesar del alto número de candidaturas que aspiran a la Alcaldía, se puede afirmar que la competencia electoral es muy inestable. De los 8 Partidos políticos, 12 Movimiento políticos y 6 Candidaturas independientes solo se registra un partido con dos participaciones consecutivas, las del "Polo Democrático Alternativo" en el 2007 y 2011. Por el lado de las candidaturas independientes, el aval para postulaciones recae en la recolección de firma. El registro del número de las firmas es el siguiente: en el 2007, Luís Fernando Cruz logró recoger 70.000 firmas, Jorge Iván Ospina 155.000 firmas y Francisco José Lloreda 201.451 firmas (Pinto, 2008:202). Por su parte, en el 2011, ${ }^{11}$ Fabio Ariel Cardozo Montealegre avaló su candidatura con 164.170 firmas y Rodrigo Guerrero Velasco ${ }^{12}$ con 115.250 firmas.

\section{Comunas: análisis del grado de nacionalización del sistema de partidos en Santiago de Cali}

En relación a los cálculos del Índice de Nacionalización (PNS), cabe mencionar que las unidades mínimas de análisis corresponden a las 22 comunas $^{13}$ y a la un espacio que se definió como General que corresponde (1) al puesto censo ${ }^{14},(2)$ a la reclu-

11 En relación a la candidatura independiente de Ramiro Jurado Donnys por "Jurado por Cali", cabe anotar que aunque su inscripción fue avalada por la Registraduría, 760 de las firmas presentadas responden a personas fallecidas. Este es mayor número de firmas de personas muertas presentadas por un candidato a nivel nacional (Registraduría, 2011:9).

12 En un primer momento, la Registraduría toma la decisión de no aprobar la inscripción Rodrigo Guerrero Velasco como candidato independiente tras el primer conteo. Según la metodología establecida desde 1996 habían suficientes rúbricas que no cumplían con los criterios constitucionales ni legales para que alcanzara al mínimo de firmas válidas. Luego de que el candidato interpusiera un recurso de reposición, las firmas se trasladaron a Bogotá para su revisión que dio como resultado la aprobación formal de su candidatura (El Espectador, 2011 y 2011 b; Montero, 2011; y Semana, 2011); sin embargo, esta decisión no dejó de ser controversial, pues, entre las 47.280 firmas que se eliminaron se registraron 12.694 casos de personas no inscritas en el censo electoral de Cali, 736 casos de personas muertas (Registraduría, 2011:9), 5.469 casos de inexistencia en el Archivo Nacional de Identificación (ANI), 4.378 casos de repeticiones, entre otros (El Espectador, 2011).

13 En el 2004 mediante el "Acuerdo 134" la comuna 17 se divide para dar origen a una nueva unidad político administrativo del Municipio de Santiago de Cali: la comuna 22 (Alcaldía de Cali, 2012).

14 El puesto censo "corresponde a sitios habilitados para que los ciudadanos con cédulas expedidas desde el 14 
sión de mujeres y (3) a la Cárcel Villanueva, lo cual constituye el límite urbano del municipio de Santiago de Cali. Los corregimientos no se incluyen en este análisis por el bajo número de votos que suman en total y por su poca incidencia en el resultado final. En promedio, los 15 corregimientos del municipio suman entre 1\% y $3 \%$ del total de votos válidos.

Para los cálculos del PNS y PSNS se tomaron los datos que ofrece la Registraduría Nacional del Estado Civil (RNEC) en su sección Histórico de los resultados electorales 1998-2012 y se indagaron los resultados de las "Autoridades Locales" que incluye elecciones a Alcaldía, Gobernación, Consejo, Asamblea y Junta Administradora Local (JAL). En la tabla 3 se presenta los valores del Índice de Nacionalización de los Partidos Políticos (PNS) y del Índice de Nacionalización del Sistema de Partidos (PSNS), para la Alcaldía del municipio de Santiago de Cali.

El Índice de Nacionalización de Partidos Políticos (PNS), en un primer momento, refleja una resultando significativamente alto, ${ }^{15}$ lo que puede entenderse como que cada candidato obtuvo distribución de su votación relativamente homogénea en cada una de las unidades de análisis. Para dar cuenta de la afirmación también podemos observar el resultado que arroja el cálculo PNS para cada uno de las opciones política en competencia.

En un segundo momento, si se observa detalladamente el PNS de los 2 candidatos más votados podremos ver un elemento que puede explicar el desarrollo de dibuja la curva del PSNS (ver gráfico 2). En el 2003 y el 2007 se repite la tendencia de que el candidato ganador obtiene un PNS superior al segundo candidato más votado; sin embargo, en el 2011 se invierten estos resultados. Ya que el cálculo del PSNS incluye la votación relativa $\left(\mathrm{P}_{\mathrm{i}}\right)$ de cada uno de los candidatos, esta inversión que ocurre en el 2011 en el cálculo de los PNS genera un efecto de jalonamiento el cual puede verse reflejando en la reducción en el PSNS de 2011.

de marzo de 1988 y que no se hubiesen inscrito en otros lugares, puedan ejercitar el derecho al sufragio en la localidad donde haya sido expedida su cédula de ciudadanía" (Definición tomada del Glosario electoral de la Registraduría General del Estado Civil, consultado desde: http://www.registraduria.gov.co/-Glosario-electoral,225-.html).

15 Jones y Mainwaring (2003), a partir del PSNS de 17 países en Latinoamérica (Argentina, Bolivia, Brasil, Canadá, Chile, Costa Rica, Ecuador, EE.UU., El Salvador, Guatemala, Honduras, Jamaica, México, Nicaragua, Perú, Uruguay y Venezuela), establecen tres categorías para comparar el grado de municipalización del sistema de partidos: baja de 0,5 a 0,8 ; intermedia 0,8 a 0,85 ; y alta de 0,85 a 1 . 


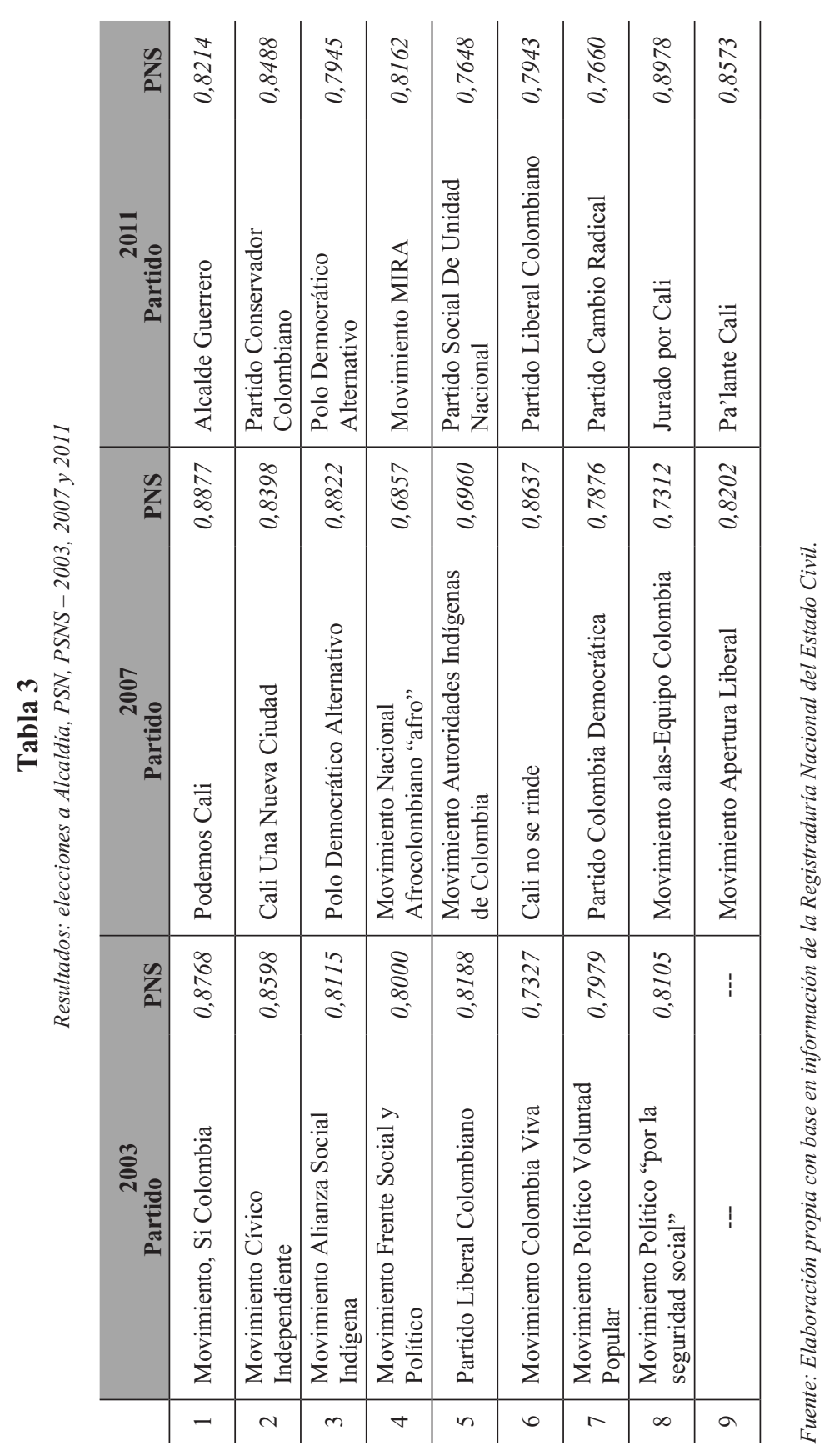




\section{Gráfico 2}

PSNS-2003, 2007 y 2011

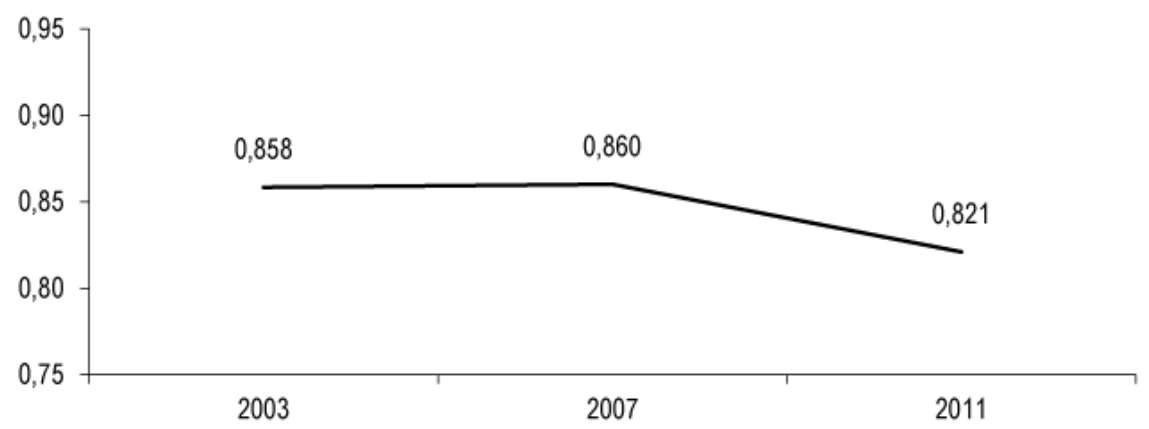

Fuente: Elaboración propia con base en información de la Registraduría Nacional del Estado Civil.

Los anteriores valores dan importantes pistas sobre el arraigo y el alcance territorial de las opciones políticas en candidatura a la Alcaldía de Cali, en la medida en que el PSNS da cuenta, consecuentemente, sobre un significativamente alto grado de penetración territorial de las opciones políticas a razón de que, en gran medida, su apoyos políticoelectorales abarcan la totalidad del territorio municipal.

\section{Votos: resultados electorales y estrato-socioeconómico}

Con tal de hacer visible los resultados que arrojó el cálculo del Índice de Nacionalización, se presenta una cartografía electoral que permite, por un lado, ilustrar el grado de homogeneidad de la competencia electoral, como, por el otro lado, compara los resultados de los dos candidatos más votados en cada periodo electoral. ${ }^{16}$ Esta comparación usa un mismo valor de referencia que corresponde a la distribución más amplia que se registra el primer y segundo candidato según en los resultados electorales en cada año. Asimismo, esta información se contrasta con un tercer mapa que representa la moda estadística de los estratos socio-económico por comuna.

16 El cálculo del Número Efectivo de Partidos Electoral (NEFe), como lo proponen Markku Laakso y Rein Taagepera (1979), arroja un valor promedio dentro del rango del número natural 2 para en las tres contiendas electorales analizadas. Esto indica el número de opciones políticas en competencia con altas probabilidades de victoria, por lo tanto, este estudio se centrará en las dos candidaturas más votadas a la Alcaldía de Cali. 
Como se puede observar comparando los tres mapas que corresponden al candidato ganador, la distribución de los votos en las jornadas electorales evidencia 2 tendencias. Por un lado, existe una significativa semejanza entre la distribución de los votos por el candidato ganador en el 2003 y 2007 por comuna a diferencia de los resultados del candidato ganador en el 2011. Por otro lado, se observa que ciertas comunas son más constantes en el número de votos por el candidato ganador que otras.

Del Mapa 1 se puede observar que la votación del candidato ganador se concentra en los estratos 2 y 3 a diferencia del candidato en segunda posición que obtiene su votación, principalmente, en las comunas donde se concentra un mayor número de barrios de estrato 5 .

El comportamiento electoral para los dos candidatos más votados en el 2007 (ver Mapa 2) se asemeja significativamente a los resultados que se registran en el 2007. Se destaca la distribución de los apoyos del candidato que obtuvo el segundo puesto, quien además repite en esta posición consecutivamente, pues obtuvo una votación por comuna muy similar y en ambas ocasiones, concentró su votación en las comunas que reúne el mayor número de barrios estrato 4 y 5 . Se podría decir que gran parte de quienes votaron por este candidato en el 2003, volvieron a votar por él en el 2007. La principal diferencia entre los candidatos ganadores en el 2003 y 2007, Apolinar Salcedo y Jorge Iván Ospina, respectivamente, consiste en que Jorge Ivan logró una mayor distribución de votos en diversas comunas que representa estratos socio-económicos 1, 2 y 3 principalmente, sin desvalorar el número de votos significativamente importante que obtuvo en los estratos 4 y 5. Se podría también decir, que el candidato ganador en el 2007 logró recoger votos en los diferentes estratos socio-económicos de la ciudad lo que permite afirmar que su apoyo electoral fue relativamente homogéneo en todo el territorio municipal.

El Mapa 3 presenta una distinción notoria en relación a los 2 mapas anteriores. Se observa que el candidato ganador, por un lado, concentró su votación en las comunas que refleja la moda en los estratos socio-económicos más altos de la ciudad, 4, 5 y 6 . Por otro lado, se observa también que Rodrigo Guerrero obtuvo un apoyo electoral relativamente homogéneo y relativamente alto en el resto de las comunas de la ciudad.

Un análisis de los tres mapas anteriores en términos del grado de nacionalización del sistema de partidos, es decir, del grado de homogeneidad de la distribución de los apoyos electorales, tendería a afirmar que los candidatos ganadores en el 2003 


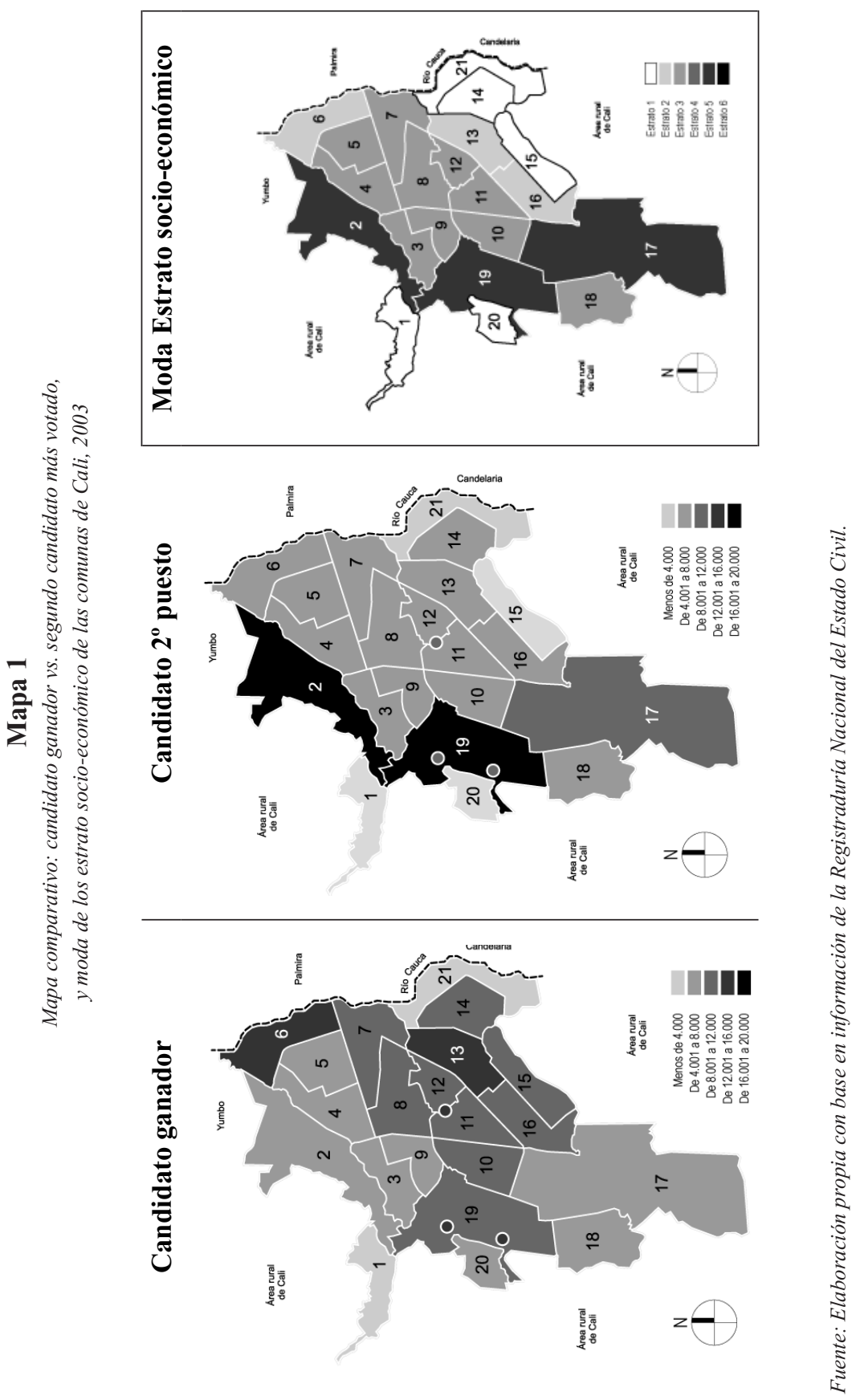




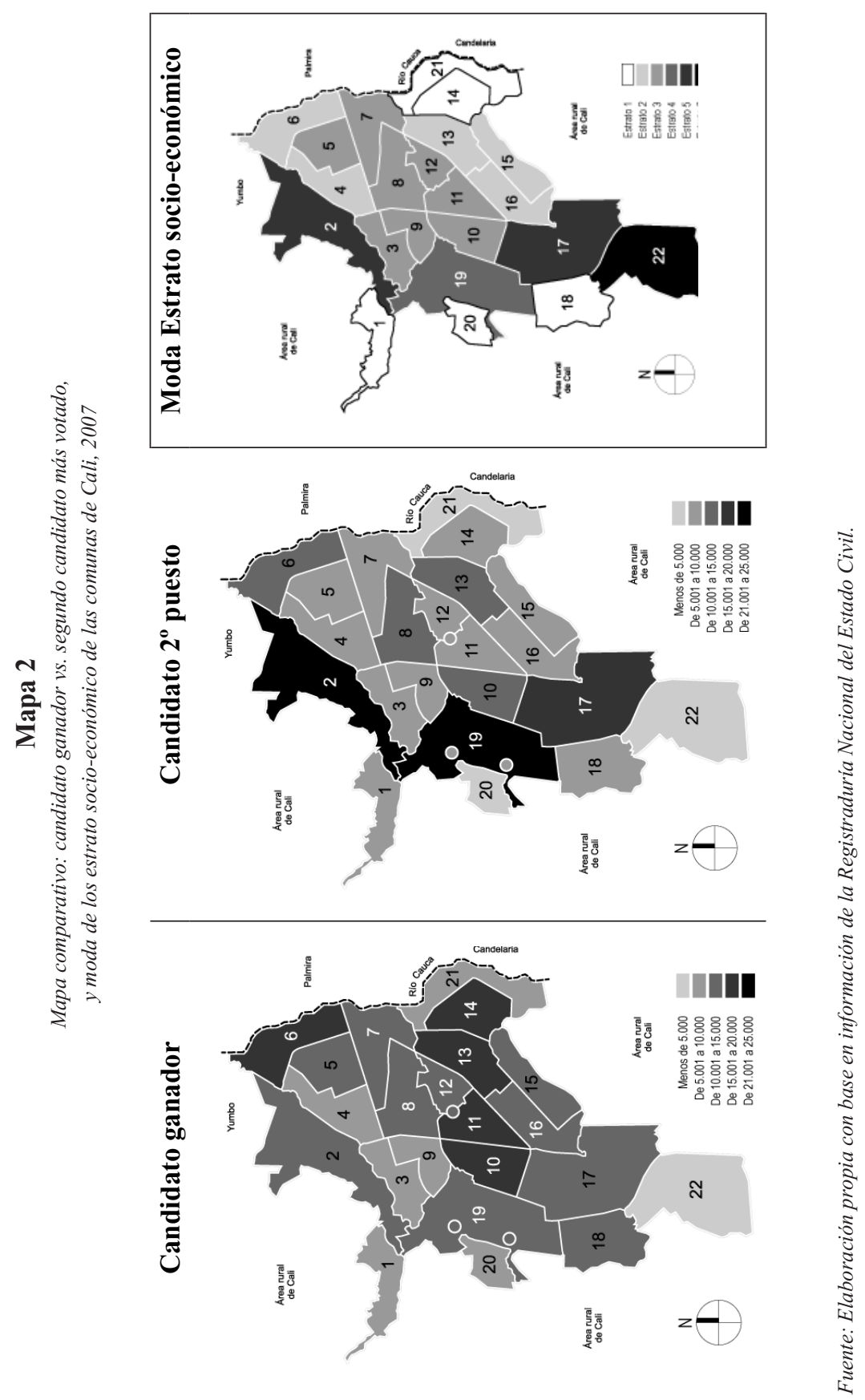




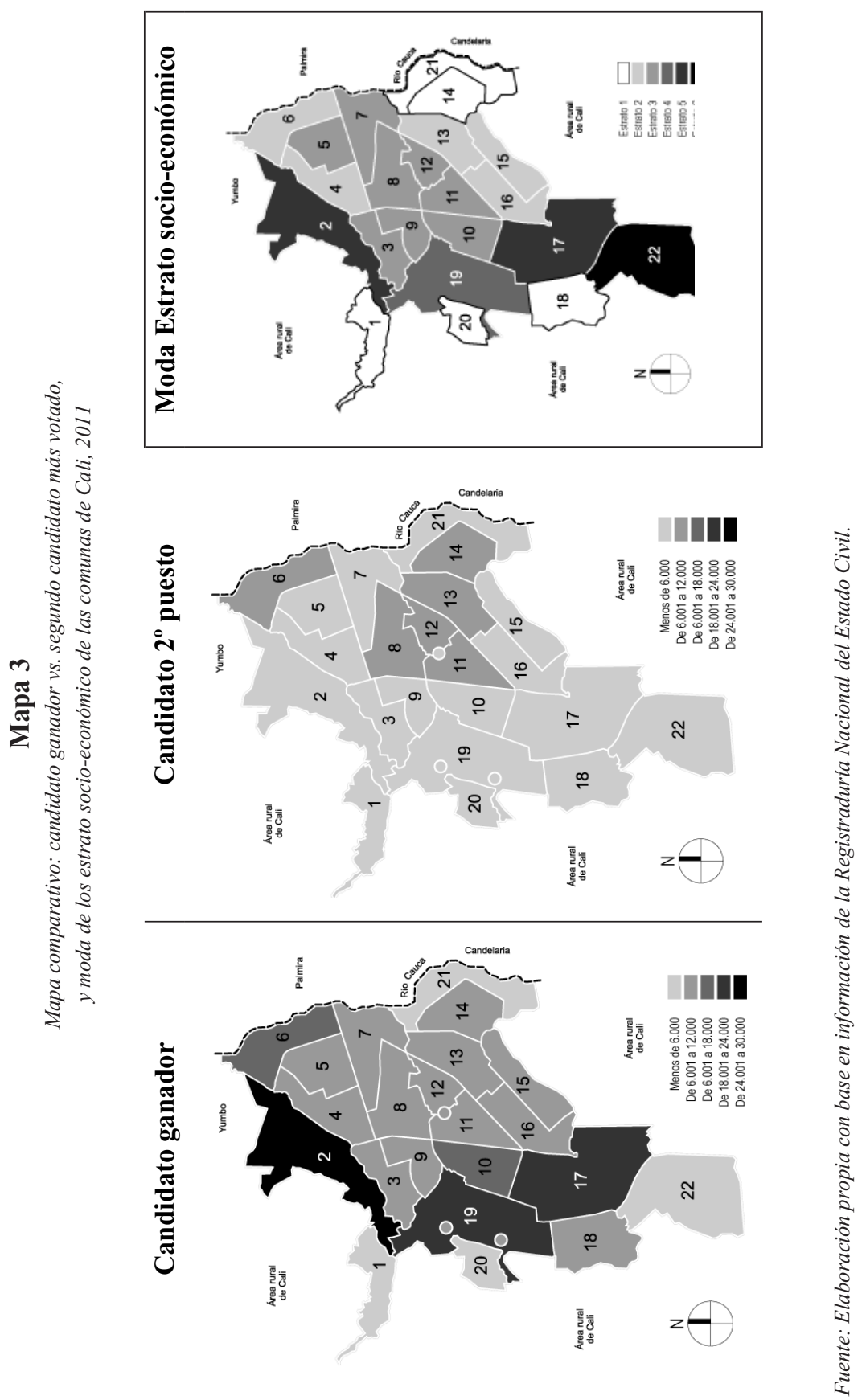


y 2007 obtuvieron un apoyo electoral significativamente más homogéneo frente al candidato que se llevó el segundo puesto en las mismas dos jornadas electorales, así como frente al candidato ganador en el 2011. Como se puede observar, un grado alto de nacionalización del partido, en este caso, candidato independiente, no se traduce automáticamente en una victoria, por un lado, porque puede existir homogeneidad en la distribución de los votos con valores significativamente bajos (ver mapa 3 del candidato en $2^{\circ}$ puesto); pero también puede ocurrir, por el otro lado, que con una distribución más dispersa de los apoyos electorales se pueda conseguir el cargo (ver mapa 3 del candidato ganador). En este segundo caso, la victoria podría entenderse como consecuencia de una fragmentación de los apoyos electorales de las otras candidaturas (Abadía y Milanese, 2014).

Otra mirada a los mismos mapas permite también observar dos relevantes tendencias. La primera se refiere al comportamiento electora de las comunas 14, 6 y 13 , de estratos 1,2 y 2 , respectivamente, que son las que mayor número de votos registran por el candidato ganador en el 2003 y 2007; a diferencia del candidato ganador en el 2011 en donde estas comunas pierden notoriamente peso. Por otro lado, como se observa en el 2011, las comunas 19,17 y 2 , de estratos 5,5 y 4 respectivamente, reemplazan completamente a las comunas anteriores en los 3 primeros puestos de las comunas que registran mayor votación por el candidato. Asimismo, la distribución de la votación por el candidato ganador en el 2011 es muy similar a la del candidato en segundo puesto en el 2003 y 2007, lo que puede estar ligado a los rasgos característicos de los perfiles de los candidatos y a la población que representa y que regularmente ha votado por cada candidato. En este sentido, si revisamos las votaciones en las tres jornadas electorales de las comunas de estrato con moda 4, 5 y 6 encontraríamos que los estratos socio-económicos más altos tienen a un comportamiento electoral significativamente similar (Abadía y Milanese, 2014) el cual se ve reflejado en una inclinación por candidatos "élite", principalmente, con una trayectoria política cercana al partido conservador. ${ }^{17}$

17 Abadía y Milanese (2014) observan que el comportamiento electoral de los estratos 1 y 2 tienden a las candidaturas "no-élite". El estrato 3 muestra un comportamiento mucho más irregular y volátil no solo entre las candidaturas "élite" y "no-elite", sino también entre una contienda electoral a la otra. 


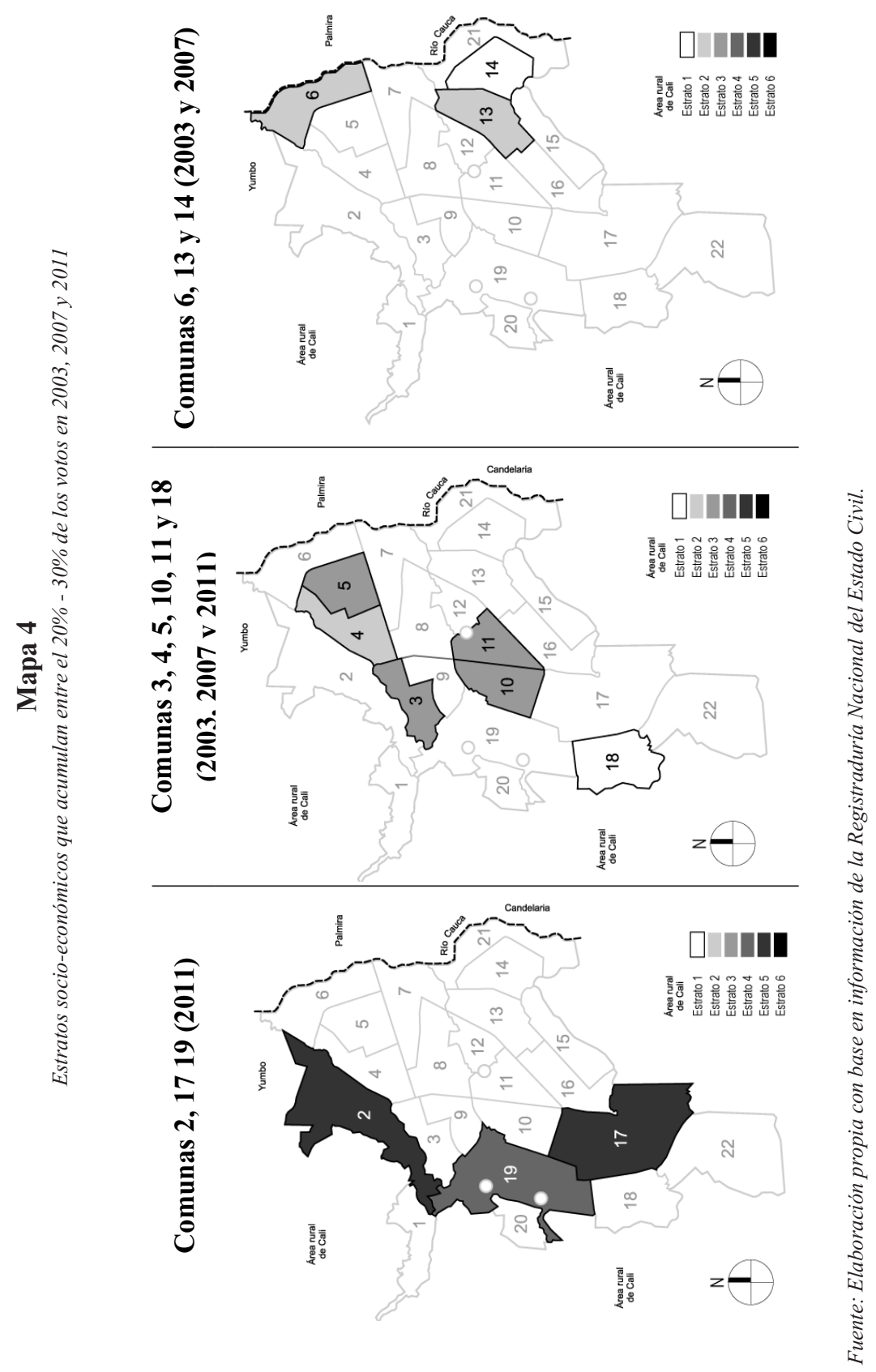


La segunda tendencia, en cierta forma menospreciada en los análisis sobre el comportamiento electoral de los caleños, se concentra en el análisis de otras comunas que guardan una significativa homogeneidad entre el número de votos relativos de una jornada electoral a otra. Entras palabras, lo que se pretende encontrar es la existencia de comunas que hayan registrado relativa baja variación en la votación por el candidato ganador. Como se observa en los resultados electorales, las comunas 3, 4, 5, 10, 11 y 18 (ver mapa 4) acumulan el mismo número de votos relativo, entre el $20 \%$ y $30 \%$, aproximadamente, que el histórico de las primeras 3 comunas que más votan por el candidato ganador en los años observados.

\section{Reflexiones finales}

En relación al comportamiento electoral y la distribución de los apoyos electorales en el caso de Cali, se observa, que no se puede generalizar la afirmación de que exista cierto número de comunas, en particular las de estrato socio-económico más bajo, que tiene una fuerte incidencia sobre la elección de un candidato político (primera hipótesis). Como se mostró, la distribución de los votos cambian completamente dependiendo del candidato que se esté postulado. Por lo tanto, las configuraciones de los apoyos electorales entre candidatos ganadores puede ser considerarse heterogénea como ocurre entre el 2007 y el 2011 (ver mapas 2 y 3). Si bien, se evidenció la existencia de una relación entre el comportamiento electoral de unas comunas respecto a ciertos candidatos, asimismo se mostró la inclinación de ciertos estratos socio-económicos por los candidatos con los que mayor identificación con algunos elementos característicos de sus perfiles políticos. En este sentido, como era de esperarse, los candidatos en cuyo perfil político se representada la élite política caleña son principalmente apoyados en los estratos más altos; por el contrario, los candidatos que afirman distanciarse de la forma (partido) y los valores de la política tradicionales (élite política) consigen mayor número de voto en los estratos más bajos.

En congruencia con lo anterior, tampoco se puede afirmar que las comunas donde un candidato ganador concentra una mayor votación vuelven a jugar un rol decisorio en las siguientes elecciones, como sugería la segunda hipótesis. Como se puede observar en la distribución de votos por el candidato ganador en 2003 y 2007, si bien estos guardan una relativa semejanza, esta situación cambia drásticamente con la distribución de votos por 
comunas del candidato ganador en el 2011. Por otro lado, si se observa detalladamente los resultados de los candidatos 2003 y 2007 (ver mapas 1 y 2), vemos que Apolinar Salcedo en 2003 obtuvo una votación relativamente más concentrada en unas comunas de estratos 1, 2 y 3 mientras que Jorge Ivan Ospina obtuvo votos significativamente altos en los diferentes estratos de la ciudad.

Por otro lado, la tercera hipótesis, el calculo del PSNS arrojó valores entre el 0,82 y 086, lo que puede catalogarse como intermedios según la escala de medición propuesta por Jones y Mainwaring (2003); por lo tanto, no se podría afirmar que el grado de nacionalización del sistema de partidos de Santiago de Cali puede considerarse como bajo. Como observamos en los mapas electorales que relacionan número de votos por comuna de los dos candidatos más votados, vemos una significativamente homogénea distribución de los apoyos políticos. Sin embargo, la concentración de los votos por los candidatos ganadores en 3 comunas en particular, evita que el PNS se aún más alto.

Finalmente, al analizar el comportamiento de los valores del Índice de Nacionalización (PNS) en las tres justas electorales, se registra una leve reducción en el grado de nacionalización del sistema de partidos de Santiago de Cali en relación a la elección de alcalde. Si bien, el descenso que se registra no permite hablar de desnacionalización habría que aguardar a futuras elecciones para poder observar si existe una tendencia hacia la desnacionalización.

Por último, si bien el desarrollo de este documento logra aportes para resolver algunas inquietudes acerca del comportamiento electoral del municipio de Santiago de Cali y desentrañar un poco las dinámicas político-electorales de cómo es la distribución de los apoyos electorales a nivel subnacional, en este caso para el municipio de Cali, este estudio abre el camino para involucrar otras instancias de elección popular, como lo es el Concejo de Cali. Un análisis que incluya estas dos instancias de poder político municipal permitiría afinar la identificación de patrones de la competencia y la participación política de los partidos, movimientos políticos, así como de las candidaturas independientes. Asimismo, este estudio del grado de institucionalización del sistema de partidos de Cali, generan otras grandes inquietudes. Por ejemplo, si bien el PNS presentó valores relativamente altos, al contrastarlo con el éxito de las candidaturas independientes, se obtiene un panorama muy diferente que deja entredicho el rol que juegan los partidos 
políticos en la elección a alcalde en Santiago de Cali. Asimismo, la inclusión de otros indicadores como el Índice de Volatilidad Electoral y el Índice de Fragmentación podrían fortalecer la idea de que las elecciones a la Alcaldía de Cali se dan en una arena política poco institucionalizada. Por otra parte, sería interesante poder desarrollar una línea de tiempo con datos históricos de los resultados electorales a la Alcaldía desde la primera elección popular de alcaldes en 1988, y de esta forma poder presentar la transformación del sistema de partido de Santiago de Cali y del impacto tanto de la caída del bipartidismo y la aparición de las candidaturas independientes, como del proceso de descentralización política. Por otra parte, valdría la pena contrastar estos resultados con otros que abordaran dinámicas electorales a otro nivel subnacional, de tal forma se podría aportar al estudio del sistema político colombiano desde una óptica multinevel y formular conclusiones con mayor nivel de profundidad.

\section{Bibliografía}

ABADÍA, Adolfo A. (2014). Grado de institucionalización del sistema de partidos en Santiago de Cali a partir del Índice de nacionalización. Elecciones a la Alcaldía 2003, 2007 y 2011. Jueves 25 de septiembre de 2014. Ponencia presentada en el III Congreso de Ciencia Política ACCPOL

ABADÍA, Adolfo A. y Juan Pablo Milanese (2014). "Impactos del perfil socioeconómico de los votantes sobre el comportamiento electoral. Análisis de las elecciones a la Alcaldía de Cali 2003-2011”. En: Revista Virtual "Renacer Jurídico”, núm. 1. Popayán, Colombia: Fundación Universitaria de Popayán

ALEMÁN, Eduardo y Marisa Kellam (2008). "The Nationalisation of Electoral Change in the Americas". En: Electoral Studies Vol. 27, pp. 193-212

ARARAT, Catalina y Jaime Londoño (2012). “Campañas electorales y publicidad política callejera: vallas, pendones, pasacalles y afiches, Cali, 2009 - 2010”. En: R. Silva, J.P. Milanese y V. Rouvinski (comp.) Desafios para la democracia y la ciudadanía. Cali: Colección El Sur es cielo roto, Universidad Icesi

ARENAS, Juan Carlos y Juan Carlos Escobar (2012). Elecciones, partidos y política 
local. Medellín: Universidad de Medellín, Instituto de Estudios políticos, Universidad de Antioquia

BATLLE, Margarita (2009). "Distribución territorial de los apoyos electorales en América Latina: Los casos de Ecuador, Perú y Honduras (1979-2006)”. En: Análisis Político, vol.22, n.67, pp. 3-20. Bogotá D.C.: Instituto de Estudios Políticos y Relaciones Internacionales (IEPRI), Universidad Nacional de Colombia.

BATLLE, Margarita y José Ricardo Puyana (2011). "El nivel de nacionalización del sistema de partidos colombiano: una mirada a partir de las elecciones legislativas de 2010". En: Colombia Internacional Núm. 74, julio a diciembre de 2011, pp.27-57. Bogotá: Ediciones Uniandes - Centro de Estudios Internacionales Departamento de Ciencia Política - Universidad de Los Andes

BOCHSLER, Daniel (2009). "Measuring party nationalisation: A new Gini-based indicator that corrects for the number of units". En: Electoral Studies, Vol. 29, pp. 155-168.

CARAMANI, Daniele (2004). The Nationalization of Politics. The Formation of National Electorates and Party Systems in Western Europe. Cambridge: Cambridge University Press

-------- (2007). “13. Party systems. The morphology of party systems". En: Comparative Politics, Caramani, Daniele (Ed.), pp. 318-347. Oxford: Oxford University Press.

CASA-GONZÁLEZ, Mauro (2010). Breve análisis sobre la evolución del sistema de partidos políticos uruguayo desde la restauración democrática, enfatizando en su relación con el sistema electoral, y en las principales consecuencias de la reforma constitucional del año 1996.

CASCANTE, María José (2010). "La competencia electoral en Costa Rica y Nicaragua: diferencias multinivel" en 200 años de Iberoamérica (1810-2010), Congreso Internacional: actas XIV encuentro de Latinoamericanistas Españoles, área temática 14, Nuevos y viejos actores: partidos, políticos y sistemas de partidos en América Latina, pp. 1893-1926. Santiago de Compostela, 15-18 de setiembre de 2010. 
CHANONA BURGUETE, Alejandro (2008). "Derechos políticos y candidaturas independientes: asignatura pendiente en la transición democrática mexicana". En: En Nueva Visión Socialdemócrata, No. 13, pp. 23-42. Mexico: Fundación por la Socialdemocracia de las Américas (FUSDA)

CORREA YOUNG, Rosalía (2012). "La descentralización en Cali: Entre avances y retrocesos". En: Perspectivas Internacionales, Vol. 8, No. 1, pp. 139-173. Cali, Colombia: Pontificia Universidad Javeriana

CRESPO-RAZEG, Faride (2010). "La élite en Cali. Algunos estudios empíricos". En: Revista CS, núm. 4, pp. 177-192. Cali: Universidad Icesi

DAADLER, Hans (2007). ¿Partidos negados, obviados, o redundantes? Una crítica”. En: Partidos Políticos. Viejos conceptos y nuevos retos, José R. Montero, Richard Gunther \& Juan J. Linz (Eds.), pp. 49-69. Madrid: Editorial Trotta, S.A.

DÁVILA LADRÓN DE GUEVARA, Andrés y Natalia Delgado Varela (2002). "La metamorfosis del sistema político colombiano: ¿Clientelismo de mercado o nueva forma de intermediación?”. En: Francisco Gutiérrez Sanín (comp.) Degradación o cambio: evolución del sistema político colombiano. Bogotá: Editorial Norma

DIAMOND, Larry \& Richard Gunther (2001). "Types and Functions of Parties". En: Political Parties and Democracy, Larry Diamond \& Richard Gunther (Eds.), pp. 3-39. Baltimore: The Johns Hopkins University Press.

(2003). "Species of political parties. A new typology". En: Party Politics, vol. 9 no.2, pp. 167-199. London: SAGE publications.

DOŠEK, Tomáš (2011). "La nacionalización de los sistemas de partidos en América Latina: explorando diversos índices de medición”. Ponencia preparada para el X Congreso de la Asociación Española de Ciencia Política y de Administración: "La política en la red". Murcia, España.

DOŠEK, Tomáš y Flavia Freidenberg (2013). "La congruencia de los partidos y los sistemas de partidos multinivel en América Latina: conceptualización y evaluación de algunas herramientas de medición”. En Politai: Revista de Ciencia Política, no. 7, pp. 
161-178. Lima, Perú: Asociación Civil Politai

GARCÍA SÁNCHEZ, Miguel (2007). "Sobre balas y votos: violencia política y participaci6n electoral en Colombia, 1990-1994”. En: Diana Hoyos (Ed) Entre la persistencia y el cambio, reconfiguración del escenario partidista y electoral en Colombia. pp. 84-117. Bogotá: Centro de Estudios Políticos e Internacionales - CEPI, Universidad del Rosario, Editorial Universidad del Rosario.

------------ (2010). “Actores armados, decisiones políticas y resultados electorales” En: EGOB - Revista de Asuntos Públicos, núm. 4, pp. 42-43. Universidad de los Andes.

GIRALDO GARCÍA, Fernando, Rodrigo Lozada Lora y Patricia Muñoz (eds.) (2001). Colombia: elecciones 2000. Bogotá: Centro Editorial Javeriano - CEJA, Pontificia Universidad Javeriana

GUTIÉRREZ SANÍN, Francisco (2006). ¿Lo que el viento se llevó? Los partidos políticos y la democracia en Colombia (1958-2002). Bogotá: Editorial Norma

INSTITUTO INTERNACIONAL PARA LA DEMOCRACIA Y LA ASISTENCIA ELECTORAL - IDEA (2006). Diseño de sistemas electorales: el nuevo manual de IDEA Internacional. Andrew Reynolds, Ben Reilly y Andrew Ellis (eds). México D.F.: Instituto Federal Electoral de México

JONES, Mark y Scott Mainwaring (2003). "The nationalization of parties and party systems: an empirical measure an application to the Americas" [en español: la nacionalización de los sistemas de partidos: una medición empírica y su aplicación en el continente americano]. En: Party Politics, Vol. 9, nº 2: 139-166. London: SAGE publications.

KATZ, Richard y Peter Mair (2007). "La supremacía del partido en las instituciones públicas: El cambio organizativo de los partidos en las democracias contemporáneas”. En: Partidos Politicos. Viejos Conceptos y Nuevos Retos, José R. Montero, Richard Gunther \& Juan J. Linz (Eds.), pp. 101-125. Madrid: Editorial Trotta, S.A.

KASUYA, Yuki y Johannes Moenius (2008). “The nationalization of party systems: Conceptual issues and alternative district-focused measures". En: Electoral Studies, núm. 27, pp. 126-135 
LAGO, Ignacio y José Ramón Montero (2010). The nationalisation of party systems revisited: A new measure based on parties' entry decisions, electoral results, and district magnitude. Trabajo preparado para la conferencia anual de la Asociación Canadiense de Ciencia Política. Montreal.

(2014). "Defining and measuring party system nationalization". En: European Political Science Review (2014), 6:2, 191-211

LAAKSO, Markku y Rein Taagepera (1979). "Effective Number of Parties: A Measure with Application to West Europe”. En: Comparative Political Studies, núm. 12, pp. 3-27

LEIRAS, Marcelo (2004). "Organización partidaria y democracia: tres tesis de los estudios comparativos y su aplicación a los partidos en la Argentina”. En: Revista SAAP, vol. 1, núm. 3, pp. 515-560. Buenos Aires: Sociedad Argentina de Análisis Político-SAAP. - (2009). Los procesos de descentralización y la nacionalización de los sistemas de partidos en América Latina. Río de Janeiro: Congreso Latin American Studies Association, del 11 al 14 de junio

LEVITSKY, Steven (1998). "Institutionalization and Peronism. The concept, the Case and the Case for Unpacking the Concept”. En: Party Politics, vol. 4, No. 1, pp. 7792. London: Social Science Collections SAGE Publications.

(2001). "Inside the Black Box: Recent Studies of Latin American Party Organizations" - Book Review Essay. En: Studies in Comparative International Development (SCID), Vol. 36, No. 2, pp. 92-110. Watson Institute for International Studies, Brown University

LLANOS ÁNGEL, Hernando (2006). “Cali, ¿Apocalypse now?”. En: Análisis Impertinentes. Reflexiones sobre política y ética en la Colombia contemporánea, pp. 281-293. Cali, Colombia: Pontificia Universidad Javeriana

LÓPEZ HERNÁNDEZ, Claudia (2010). Y refundaron la patria... De cómo mafiosos y políticos reconfiguraron el Estado colombiano. Barcelona, España: Random House Mondadori S.A. 
LUPU, Noam (2008). Nationalisation and Party Institutionalization in Twentieth-Century Argentina. Paper prepared for presentation at the Conference on Party-System Institutionalization in Latin America, CIDOB Foundation, Barcelona, November 20-21, 2008.

MAINWARING, Scott y Edurme Zoco (2007). "Secuencias políticas y estabilización de la competencia partidista: volatilidad electoral en viejas y nuevas democracias". En: América Latina Hoy, 46, pp. 147-171. Ediciones Universidad de Salamanca.

MAINWARING, Scott y Mariano Torcal (2005). "La institucionalización de los sistemas de partidos y la teoría del sistema partidista después de la tercera ola democratizadora”. En: América Latina Hoy, 41, pp. 141-173. Ediciones Universidad de Salamanca.

MAINWARING, Scott y Timothy R. Scully (1995). "La institucionalización de los sistemas de partidos en América Latina”. En: Revista de Ciencia Política, vol. XVII, No. 1-2, pp.63-101.

MILANESE, Juan Pablo (2014). ¿Aguablanca elige al Alcalde? "Guía práctica" para ganar una elección municipal en Cali. Jueves 25 de septiembre de 2014. Ponencia presentada en el III Congreso de Ciencia Política ACCPOL

MILANESE, Juan Pablo y Luis Eduardo Jaramillo (2013). Impacto de los factores institucionales del sistema electoral en la fragmentación partidaria. Un análisis de las elecciones para concejos municipales en el Valle del Cauca (1997-2011), Ponencia presentada en el 7o. Congreso Latinoamericano de Ciencia Política ALACIP

OBSERVATORIO DE PROCESOS ELECTORALES - OPE (2008). "Estudio comparado de las barreras o umbrales electorales implícitos y explícitos en el sistema electoral". En: Documentos de Trabajo, No. 2, Proyecto fortalecimiento de la democracia en Colombia, PNUD-IDEA Internacional. Bogotá: Facultad de Ciencia Política y Gobierno de la Universidad del Rosario

OBSERVATORIO DE POLÍTICAS PÚBLICAS - POLIS (2011). Factores y mapas de riego electoral. Alcaldía de Cali 2003 y 2007. Cali, Universidad Icesi. Consulta realizada desde: http://issuu.com/polisicesi/docs/dpp2011-02_completo 
OCAÑA, Francisco y Pablo Oñame (1999). "Índices e indicadores del sistema electoral y del sistema de partido. Una propuesta informática para su cálculo". En: Revista Española de Investigaciones Sociológicas (Reis), No.86, pp. 233-245. Madrid: Centro de Investigaciones Sociológicas (CIS).

PEDERSEN, Mogens (1990) “Electoral volatility in Western Europe: 1948-1977”. En Mair, Peter. The West European party system. Oxford: Oxford University Press.

PINTO OCAMPO, María Teresa (2008). "La disputa política en torno a la alcaldía de Santiago de Cali de 2007”. En: Sociedad y Economía, No 14, pp. 201-226. Cali, Colombia: Universidad del Valle

PINTO OCAMPO, María Teresa (2011). "Mecanismos en la transformación política en Cali: fragmentación partidista, electorado cambiante y responsabilidad política (19882007)”. En: Estudios Políticos, No. 39, pp. 15-38. Medellín: Universidad de Antioquia

SÁENZ, José Darío (2010a). Élite politica y construcciones de ciudad. Cali 19581998. Cali: Colección Exploraciones, Universidad Icesi. (2010b). "Configuración de una elite política en Cali: 1958-1998”. En: Revista CS, núm. 4, pp. 147-175. Cali: Universidad Icesi

SARTORI, Giovanni (2005). "El partido como una parte". En: Partidos y Sistemas de Partidos. Marco para un Análisis, capítulo 1, pp. 27-67. Madrid: Editorial Alianza.

SCHAKEL, Arjan H. (2012). "Nationalisation of multilevel party systems: A conceptual and empirical analysis". En: European Journal of Political Research, first published online August 12

SCHMITTER, Phillip (1999). "Critical Reflexions on the "Functions" of political parties and their Perfomance in Neo-Democracies". En: Demokratie in Ost und West, Wolfgang Merkel and Andreas Busch (Eds.), pp. 475-495. Frankfurt/M.: Suhrkamp Verlag GmbH und Co. KG.

TALBOT DE CAMPOS, Judith y José Francisco Martín (1980). El comportamiento electoral en Cali, 1978. Cali, Colombia: Centro de Investigaciones y Documentación 
Socio-Económica (CIDSE), Universidad del Valle y Fundación Friedrich Naumann

URDÁNOZ G., Jorge (2008). "Umbrales de representación y proporcionalidad". En: Revista Española de Investigación (Reis), No.121, pp. 133-166. Madrid: Centro de Investigaciones Sociológicas (CIS).

\section{Fuentes normativas}

CONCEJO NACIONAL ELECTORAL - CNE (2006). Resolución 1057 de 2006. Consulta realizada desde: http://www.cne.gov.co/CNE/media/file/1057.PDF

\section{LEY 130 DE 1994}

REGISTRADURÍA NACIONAL DEL ESTADO CIVIL (2011). Denuncia penal. Consulta realizada desde: http://www.registraduria.gov.co/descargar/denuncia_penal_ elec2011.pdf

\section{Referencia a datos estadísticos}

REGISTRADURÍA NACIONAL DEL ESTADO CIVIL (2010). Histórico. Resultados electorales 1998-2010. Consulta realizada el 13 de Octubre de 2012, desde http://www.registraduria.gov.co/Informacion/elec_pre_2010_histo.htm para los resultados de las elecciones de los años de 2003, de 2007 y de 2011; y desde http:// www.registraduria.gov.co/Elecciones/2010e26_cam_dptal.htm para los resultados de las elecciones de 2010 .

DEPARTAMENTO ADMINISTRATIVO NACIONAL DE ESTADÍSTICA DANE (2005). Estimaciones de población 1985-2005 y proyecciones de población 2005-2020. Total municipal por área. Consulta realizada el 13 de Enero de 2014, desde http://www.dane.gov.co/files/investigaciones/poblacion/proyepobla06_20/ Municipal_area_1985-2020.xls

ALCALDÍA DE CALI (2004). Cali en cifras 2003. Santiago de Cali, Colombia: Departamento Administrativo de Planeación (DAP). Consultado desde www.cali. gov.co/descargar.php 
(2008). Cali en cifras 2007. Santiago de Cali, Colombia: Departamento Administrativo de Planeación (DAP). Consultado desde www.cali.gov.co/descargar.php ------------ (2012). Cali en cifras 2011. Santiago de Cali, Colombia: Departamento Administrativo de Planeación (DAP). Consultado desde www.cali.gov.co/descargar.php

\section{Documentos de prensa}

EL ESPECTADOR (2011). "En listas de Rodrigo Guerrero aparecen firmando 736 muertos". En: El Espectador, agosto 29. Consulta realizada el 9 de noviembre de 2013, desde: http://www.elespectador.com/noticias/politica/listas-de-rodrigo-guerreroaparecen-firmando-736-muerto-articulo-295490

- (2011a) "Jorge Iván Ospina seguiría como alcalde pese a fallo de la Procuraduría". En: El País, diciembre 14. Consulta realizada el 9 de noviembre de 2013, desde: http://www.elpais.com.co/elpais/cali/noticias/suspenden-por-6-mesesalcalde-cali-jorge-ivan-ospina

(2011b). “¿Corrupción electoral en Cali?”. En: El Espectador, agosto 22. Consulta realizada el 9 de noviembre de 2013, desde: http://www.elespectador.com/ impreso/politica/articulo-293711-corrupcion-electoral-Cali

EL TIEMPO (1997). "Impuestos, reto de aspirantes a alcaldía". En: El Tiempo, octubre 26. Consulta realizada el 9 de noviembre de 2013, desde: http://www.eltiempo. com/archivo/documento/MAM-663176

MONTERO, Dora (2011a). "El Registrador está dispuesto a contar una a una las firmas de Susana Correa y Rodrigo Guerrero". En: La Silla Vacía, Agosto 23. Consulta realizada el 9 de noviembre de 2013, desde: http://asillavacia.com/ historia/el-registrador-esta-dispuesto-contar-una-una-las-firmas-de-susana-correay-rodrigo-guerrero

----------(2011b). “Rodrigo Guerrero”. En: La silla vacía, septiembre 27. Consulta realizada el 26 de mayo de 2014, desde: http://lasillavacia.com/perfilquien/27860/ rodrigo-guerrero 
(2011c). "Milton Castrillón". En: La silla vacía, septiembre 27. Consulta realizada el 26 de mayo de 2014, desde: http://lasillavacia.com/perfilquien/27859/ milton-castrillon

SEMANA (2011). “Dónde está el torcido?”. En: Revista Semana, agosto 29. Consulta realizada el 9 de noviembre de 2013, desde: http://www.terra.com.co/elecciones_2011/ votebien/html/vbn1390-donde-esta-el-torcido.htm 
